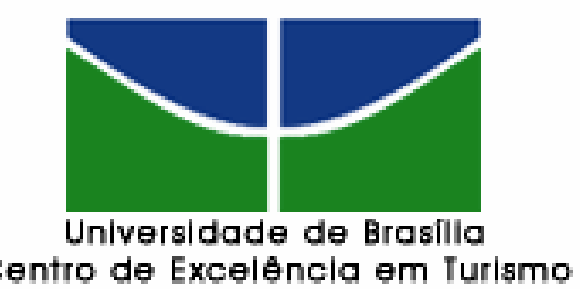

Centro de Excelêncla em Turismo

\title{
AVALIAÇÃO DO NÍVEL DE SATISFAÇÃO DE OPERADORES DE UMA UNIDADE DE ALIMENTAÇÃO E NUTRIÇÃO HOSPITALAR
}

\author{
Ana Helena Sampaio Maluf \\ Patrícia Costa Bezerra, MSc
}

Monografia apresentada ao Centro de Excelência em Turismo da Universidade de Brasília como requisito para a obtenção do certificado de Especialista em Qualidade em Alimentos.

Brasília-DF, Janeiro/2003 


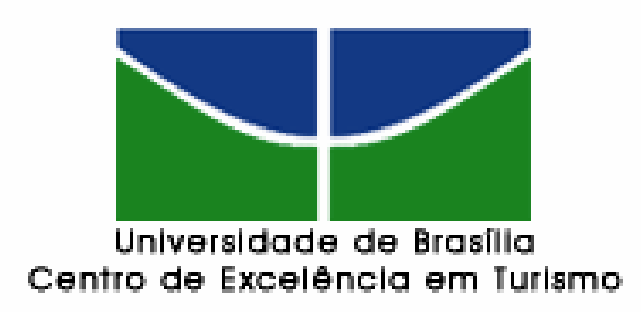

Curso de Especialização em Qualidade em Alimentos

\title{
AVALIAÇÃO DO NÍVEL DE SATISFAÇÃO DE OPERADORES DE UMA UNIDADE DE ALIMENTAÇÃO E NUTRIÇÃO HOSPITALAR
}

\author{
Ana Helena Sampaio Maluf \\ Aluna \\ Patrícia Costa Bezerra, MSc. \\ Orientadora \\ Domingos Sávio Spezia, MSc \\ Membro da Banca
}

Brasília-DF, Janeiro/2003 
Maluf, Ana Helena Sampaio

Avaliação do nível de satisfação de operadores de uma Unidade de Alimentação e Nutrição hospitalar/Ana Helena Sampaio Maluf - Brasília, 2003.

vii, 39p.

Monografia (especialização)-Universidade de Brasília. Centro de Excelência em Turismo.

Assessment of job satisfaction level of hospital food service employees.

$\begin{array}{ll}\text { 1. Satisfação no Trabalho } & \text { 2. Motivação }\end{array}$

3. Unidade de Alimentação e Nutrição 
Ao meu querido irmão José Maria que sempre tem uma mão estendida para me socorrer e que fez tudo ser possível. A todos meus amigos da nutrição do Hospital da Rede-Sarah ao qual devo minha lição diária de vida, coragem, fé, obstinação e alegria. Agradeço a enorme paciência. E a Eduardo Kerterz (in memória) pela mais pura tradução da palavra amigo. 


\section{AGRADECIMENTOS}

DEUS, que através do meu mentor espiritual esteve sempre em meu auxilio.

Patrícia Bezerra, por compartilhar seus conhecimentos orientando-me de uma forma tão delicada e amorosa tornando este trabalho muito prazeroso.

Gertrudes, pela valorosa contribuição na tradução dos dados estastísticos.

Denise, por ajudar-me a expressar-me com correção as minhas idéias.

Carla, pela transferência de suas experiências orientando-me na elaboração do questionário e escolha bibliográfica.

Paulo Ismael, pela participação carinhosa tornando este trabalho especial.

As bibliotecárias do Hospital Sarah pela eficiência e competência com que me auxiliaram.

Flávia e Luis Guilherme pela orientações em estatística.

Ademir Berti, o meu sempre mestre.

Thaís, pela fundamental ajuda durante todo o meu curso. Que bom ter você sempre perto.

Giu, por sua importante contribuição na revisão de textos.

A todos os nutricionistas amigos que durante o curso com muita paciência supriram minha deficiência no inglês.

Gaúcho, Cid e Reza, pela fantástica ajuda nos trabalhos acadêmicos.

Ailton e Lúcio pelo apoio fundamental sem o qual tudo seria muito mais difícil.

Sonia e Beth, pelo empréstimo de importantes referenciais bibliográficas.

Maria Áurea e Andréa pelo empréstimo de seus companheiros.

Paulo pela imensa compreensão.

Aos meus colegas de turma Solange, Kellen, Margaridinha e Sósigeno sem os quais o curso não teria a mesma graça. 
Dr. Campos, pela capacidade de construir uma Instituição na qual me dá enormes condições de crescimento.

Fares, minha energia vital.

Aos meus filhos (Yuri, Ana Júlia e Ana Chisthina), que são a razão de tudo. 
"Um homem se humilha, se castram seus sonhos seu sonho é sua vida e a vida é o trabalho e sem o seu trabalho um homem não tem honra e sem a sua honra se morre se mata não dá pra ser feliz, não dá pra ser feliz”.

(Gonzaguinha). 


\section{RESUMO}

O presente estudo teve como objetivo identificar o grau de satisfação dos funcionários de uma UAN - Unidade de Alimentação e Nutrição hospitalar por meio da aplicação de uma escala de prazer-sofrimento, segundo uma abordagem da psicodinâmica do trabalho. Para a realização do estudo, aplicou-se questionário a 70 operadores deste setor que estavam em escala de serviço durante o período de coleta de dados. O instrumento utilizado continha informações que avaliaram o perfil demográfico, tempo de trabalho na instituição e no setor, além de questões relacionadas à satisfação aos valores atribuídos ao trabalho. As questões relacionadas à satisfação no trabalho foram adaptadas do modelo proposto por Mendes (A.M. Mendes, Validação de uma escala de indicadores de prazer e sofrimento no trabalho, Publicação interna do Instituto de Psicologia, Universidade de Brasília, Brasília, 2002, no prelo). As questões foram apresentadas em uma escala de concordância de 5 pontos, onde 1 corresponde a não concordo até 5 que corresponde a concordo totalmente. Para a análise dos dados, as respostas foram categorizadas em quatro grupos, sendo dois deles indicadores de prazer e dois indicadores de sofrimento. Os indicadores de prazer são obtidos por meio do fator gratificação e do fator liberdade no trabalho. Os fatores indicadores de sofrimento são obtidos a partir do fator desgaste e do fator insegurança. Os resultados obtidos a partir da escala de avaliação de prazer-sofrimento indicaram predomínio dos indicadores de prazer, sugerindo que a amostra apresentou elevado grau de satisfação no trabalho. Os operadores sentem-se realizados e consideram o respeito adquirido o item mais importante de seu trabalho, seguido do item salário.

Palavras-chaves: Satisfação no trabalho, Motivação, Unidade de Alimentação e Nutrição. 


\begin{abstract}
This study was designed to identify the level of job satisfaction found in hospital food service employees, through the application of a pleasure-suffering scale, according to the psychodynamics of work approach. For the accomplishment of the study, a protocol was applied to the 70 operators which were in service scale during the period of data collection. The used instrument contained subjects that assess the demographic profile, time of work in the institution and in the section, besides subjects related to the satisfaction and to the values attributed to the work. The subjects related to the job satisfaction were adapted of the model proposed by Mendes (A. M. Mendes, $S$, Instituto de Psiclogia, Universidade de Brasília, Brasília, 2002, Preprint). The subjects were presented in a scale of agreement of five points, where 1 stands for I don't agree, up to 5 that stands for I fully agree. For the analysis of the data, the answers were classified in four groups, being two of them pleasure indicators and two suffering indicators. The pleasure indicators are obtained through a gratification factor and a freedom factor in the work. The indicative factors of suffering are obtained from a consuming factor and an insecurity factor. The results obtained from the pleasure-suffering scale of evaluation indicated prevalence of the pleasure indicators, suggesting that the sample presented high satisfaction degree in the work. The operators share a sense of self-realization, and they consider the acquired respect the most important item of their work, following by the item wage.
\end{abstract}

Key Words - Job Satisfaction, Motivation, Hospital food service. 


\section{SUMÁRIO}

RESUMO

ABSTRACT

VII

ABSTRACT

INTRODUÇÃO

1. REVISÃO DE LITERATURA

1.1 O trabalho na Unidade de Alimentação e Nutrição 03

1.2 Trabalho: Sofrimento, Prazer e Motivação 04

1.3 Motivação e Satisfação no Trabalho em Unidade de Alimentação e Nutrição 06

2. METODOLOGIA

2.1 Sujeitos 10

$\begin{array}{ll}2.2 \text { Critérios de Inclusão } & 10\end{array}$

$\begin{array}{lll}2.3 & \text { Instrumentos } & 10\end{array}$

2.4 Análise de dados 11

3. RESULTADOS 12

4. DISCUSSÃO

4.1 Características da Amostra 32

4.2 Os Indivíduos de Prazer-Sofrimento na UAN 33

$\begin{array}{ll}\text { CONCLUSÃO } & 35\end{array}$

$\begin{array}{ll}\text { ANEXO } & 36\end{array}$

$\begin{array}{ll}\text { REFERÊNCIAS BIBLIOGRÁFICAS } & 38\end{array}$ 


\section{INTRODUÇÃO}

O que pode motivar pessoas que exercem profissões de pouco reconhecimento social? Empregados, mesmo que trabalhem pela necessidade e não por aspirações pessoais podem se manter motivados? Como transformar tarefas "pesadas”, repetitivas, em algo prazeroso? Quando se coordena uma equipe de empregados operacionais de nível básico, como avaliar o nível de satisfação no trabalho realizados pelos funcionários. O indivíduo que compõe o quadro funcional de uma UAN, normalmente, não está neste trabalho por escolha, por vocação. Muitas dessas pessoas são levadas a esta ocupação por uma questão de sobrevivência. Tornando assim trabalhadores e não profissionais, que acabam exercendo funções operacionais por não terem, na maioria das vezes, qualificações para outras. Conceitos como obrigação, castigo, mal necessário até meio de realização humana são utilizadas para definir trabalho. O trabalho faz parte da condição humana e confere ao homem realização e identidade, podendo assumir diferentes significados, de acordo com o contexto vigente.

Considerando o crescimento e a importância que o setor de alimentação tem na sociedade atual, torna-se necessário o desenvolvimento de estratégias e habilidades que conduzam a uma melhora na produtividade e na qualidade dos serviços prestados por funcionários deste setor. Estratégias e habilidades que devem ser criadas para o aprimoramento dos operadores e principalmente para as lideranças, visando promover no seu grupo de trabalho a satisfação, a qualidade de vida necessários à saúde e conseqüentemente ao aumento na produtividade do trabalhador.

A satisfação e o prazer no trabalho têm sido objeto de estudo de diversas áreas, como a Psicologia, a Economia, e a Administração. Entretanto existem poucos estudos que orientem profissionais na Área de Alimentação e Nutrição que buscam manter a satisfação dos trabalhadores de uma UAN hospitalar.

O objetivo central deste estudo é avaliar o prazer e o sofrimento em trabalhadores de Unidade de Alimentação e Nutrição (UAN) hospitalar, usando como base teoria e abordagem da psicodinâmica do trabalho. 
O presente estudo teve como objetivo gerais identificar o grau de satisfação dos funcionários de uma UAN hospitalar por meio da aplicação de uma escala de prazer-sofrimento no trabalho.

\section{Como objetivos específicos visa:}

-Atualizar a literatura sobre o grau de satisfação no trabalho aplicado à UAN

- Conhecer os índices demográficos da população a inquerir;

- Identificar fatores que interferem na vivência do prazer e do sofrimento dos operadores da UAN hospitalar. 


\section{1 - REVISÃO DE LITERATURA}

\section{1 - O trabalho na Unidade de Alimentação e Nutrição}

O setor de Alimentação Coletiva é representado por todos os estabelecimentos envolvidos com a produção e distribuição de refeições para coletividades sadias ou enfermas, sendo portanto, de grande importância econômica e social. O objetivo de uma Unidade de Alimentação e Nutrição (UAN) é fornecer refeições equilibradas nutricionalmente, com sanidade, e adequada à população, visando manter ou recuperar a saúde do indivíduo (Proença, 1999; Proença \& Matos, 1996).

A produção e distribuição de alimentos são norteadas por condutas técnicas, que quando não cumpridas podem tornar os alimentos inadequados ao consumo, desta forma classificadas como atividades de alta complexidade. Para o cumprimento desta atividade devem ser garantidas condições ambientais que envolvem aspectos relacionados a ruídos, temperatura, umidade, ventilação, iluminação, gases, vapores, resíduos tóxicos, bem como espaço físico e equipamentos. Além de considerar os aspectos ergonômicos e que assegurem a saúde física do trabalhador, deve-se também considerar as questões que envolvem a saúde psíquica, uma vez que provocam reflexos evidentes na qualidade do produto final (Proença \& Matos, 1996).

Vários trabalhos que avaliam as condições ergonômicas, o estado de saúde e a qualidade de vida de trabalhadores de uma UAN têm sido conduzidos (Matos \& Proença, 2001; Veiros e cols, 1998; Proença \& Matos, 1996). Entretanto, pouco se investiga sobre a satisfação e motivação deste grupo.

O ambiente de trabalho adverso, caracterizado por alguns autores como um trabalho repetitivo, temperatura elevada, umidade alta, grande período de permanência em pé, levantamento de peso e estresse para cumprir tarefas entre outros, podem gerar insatisfações, cansaço excessivo, queda de produtividade, problemas de saúde e acidentes de trabalho. A preocupação com a saúde do trabalhador surge, à medida em que se nota 
relação de condição e da satisfação com o trabalho com performance e produtividade (Matos \& Proença, 2001).

\section{2 - Trabalho: sofrimento, prazer e motivação.}

Segundo Mendes (no prelo) o trabalho faz parte da condição humana, e como tal é indissociável da existência. O trabalho pode ser visto como um meio de subsistência, um mal necessário, obrigação ou ainda como um meio de dignificar o homem. O trabalho que é realizado para atender as necessidades de consumo, desenvolvimento social pode também possibilitar ao homem construir-se a si mesmo e marcar sua existência no mundo. Além de atender às necessidades básicas e de segurança, é um dos caminhos para o prazer porque cria identidade social e pessoal. Entretanto, o trabalho também pode ser visto como algo penoso e doloroso, como uma forma de sofrimento, contribuindo inclusive para o desenvolvimento de doenças (Mendes, no prelo); (Dejours, 1999; Dejours, 1992).

Mendes (no prelo) aponta o trabalho como um caminho, na vida adulta, de construção da identidade. O trabalhador ao produzir algo estrutura-se como pessoa em decorrência do reconhecimento do seu fazer pelo "outro"- hierarquia, pares e familiares.

Dejours (1992) enfatiza o papel do trabalho para alcance do equilíbrio psíquico e físico de um indivíduo. Segundo este autor, o trabalho pode conferir ao organismo maior resistência contra a fadiga e a doença. O trabalho revela-se ainda como um mediador privilegiado, senão único, entre inconsciente e campo social e entre ordem singular e ordem coletiva. Indica a conquista da identidade, da continuidade e da historicização do sujeito (Dejours \& Abdoucheli, 1994).

Ainda para Dejours(1992), o trabalho apresenta-se com uma forma favorável, não conflituosa quando uma das seguintes condições é encontrada:

- As exigências intelectuais, motoras ou psicossensoriais da tarefa vão ao encontro das necessidades do trabalhador considerado, de tal maneira que o simples exercício da tarefa gera prazer;

- O conteúdo, o ritmo do trabalho e do modo operatório é, em parte deixada ao trabalhador. Este pode, então, modificar a organização de seu trabalho conforme seu desejo ou suas necessidades, seus próprios ritmos biológicos, endócrinos e psicoafetivos. O sofrimento emerge quando há conflitos entre as expectativas 
(projetos, esperanças e desejos) do trabalhador e da organização do trabalho ou quando tais expectativas são ignoradas.

Morrone (2001) destaca quatro sentimentos indicadores da vivência de sofrimento no trabalho, a partir de pesquisas que analisaram o discurso dos trabalhadores. São eles: sentimentos de indignidade, inutilidade relacionado à falta de qualificação e finalidade do trabalho, desqualificação e finalmente o sentimento de vivência depressiva. Como sentimento de indignidade, a autora refere-se à tarefa desinteressante, robotizada, que não exige imaginação e inteligência, resultando na falta de significação e em frustração narcísica. O sentimento de inutilidade está relacionado ao desconhecimento da finalidade do seu trabalho. Já o sentimento de desqualificação está ligado à imagem do trabalhador, imagem relacionada ao grau de admiração que o coletivo imprime à tarefa. O sentimento de vivência depressiva condensa os três anteriores, ampliando-os ao associar-se à sensação de adormecimento intelectual.

Fundamentado em concepções teóricas propostas pela abordagem psicodinâmica, Mendes (no prelo) descreve conceitualmente indicadores que podem ser utilizados em pesquisas que estudem a relação prazer-sofrimento no trabalho. Os indicadores de prazer são a gratificação e a liberdade no trabalho. Gratificação é definida como sentimento de satisfação, realização, orgulho e identificação com um trabalho que atende às aspirações profissionais. O fator liberdade no trabalho é definido como um sentimento de liberdade de pensamento, emissão de opiniões sobre o trabalho e autonomia para se organizar, sendo tais condutas legitimadas pela chefia e por colegas. Os indicadores de sofrimento são apresentados pelos fatores de desgaste e insegurança. O fator desgaste é definido como o sentimento de que o trabalho causa estresse, sobrecarga, tensão emocional, cansaço, ansiedade, desânimo e frustração. Por insegurança, entende-se o receio de perder o emprego e de não conseguir atender às expectativas relacionadas à competência profissional, exigência de produtividade e pressões no ambiente de trabalho.

Outras teorias têm sido propostas para investigar a satisfação e a motivação do trabalho. Maslow (1970) ao avaliar fatores de satisfação e insatisfação de trabalhadores, apresenta sua teoria sobre motivação. Segundo esse autor, a motivação é produto de uma permanente necessidade de satisfação, onde as necessidades organizam-se de forma hierárquica. Dessa forma, à medida em que as necessidades básicas são satisfeitas, outras, 
de níveis mais elevados, assumem prioridade. Conforme este modelo, as necessidades podem ser primárias (fisiológicas e segurança) ou secundárias (sociais, estima e autorealização). Motivação provém de necessidades intrínsecas ao individuo, não podendo ser implantadas em seu interior por elementos externos.

Segundo Silva (2001) citado por Leite (2002) “as necessidades fisiológicas são instintivas e já nasceram com os indivíduos, são os mais prementes de todas as necessidades humanas e dirigem o comportamento do indivíduo quando estão insatisfeitos”. A necessidade de segurança refere-se à proteção contra a ameaça de perder a capacidade de satisfazer as exigências fisiológicas (desemprego, roubo, etc...). Por necessidade social, entende-se aquela carência do homem inserir-se em grupos (amigos, família, colegas e instituições). Esses pertencimento aufere uma proteção que os grupos formais e informais propiciam. A estima refere-se à necessidade de reconhecimento, de ser visto individualmente e gozar do respeito dos outros. Esta quando contemplada provoca sentimentos de auto-confiança. A auto-realização é a necessidade de realização plena de seu potencial. O indivíduo torna-se aquilo que é capaz de ser.

É importante destacar que, segundo Maslow (2000), o grau das necessidades difere de individuo para individuo, as necessidades possuem diversas potências, e que as pessoas serão motivadas a comportarem-se de maneira a satisfazer a necessidade mais premente. A Teoria de Maslow deve ser considerada como uma orientação geral, pois trata de conceitos relativos, porém não explica todo o comportamento humano.

\section{3 - Motivação e satisfação no trabalho em Unidades de Alimentação e Nutrição.}

Sneed \& Herman (1990) avaliaram a influência das características do trabalho e da organização sobre a satisfação no trabalho de funcionários do setor de alimentação de hospitais. Foram avaliados por meio de questionários 45 funcionários supervisores e 172 não supervisores em 11 hospitais randomicamente selecionados. Os resultados indicaram que a variedade de tarefas e o feedback foram as características melhores relacionadas à satisfação no trabalho e ao compromisso com a organização. Os autores também descrevem que tais características são as mais facilmente modificáveis em uma organização e sugerem seu emprego como uma estratégia para a motivação de funcionários.

Proença \& Matos (1996) observaram diretamente e entrevistaram 14 operadores de Unidades de Alimentação e Nutrição de creches municipais de Florianópolis (SC) para 
valiar as condições ergonômicas, de saúde no trabalho e o nível de satisfação destes funcionários. Os resultados indicaram que 76,5\% da amostra apresentaram algum problema de saúde. Foram relatados incidências de $46 \%$ de problemas na coluna e $47 \%$ de dores nas costas, provavelmente devido a alta ocorrência de esforços e postura inadequadas. Todos os entrevistados apontaram problemas no setor (os mais citados foram falta de espaço, calor, excesso de peso) e mesmo assim o índice de satisfação com o trabalho foi de 88,3\%. Segundo os entrevistados o nível de satisfação deve-se ao bom relacionamento com as pessoas do local (35\%) e ao fato de gostarem de trabalhar com crianças. Os autores destacaram ainda que apesar de $100 \%$ da amostra indicar algum tipo de problema no setor há falta de credibilidade na mudança destas condições, caracterizando uma sensação de conformidade nesta população. Tal conformação, associada ao sentimento de valorização, foram os principais responsáveis pelo alto índice de satisfação segundo Proença \& Matos (1996).

DeMicco \& Olsen (1988) investigaram o fluxo de trabalhadores antigos nos serviços de alimentação a fim de determinar como os vários aspectos dos seus trabalhos afetam sua satisfação e engajamento, e deste modo, sua intenção de permanecer no trabalho, protelando suas aposentadorias. Foi feito um levantamento de dados de 243 trabalhadores de nível não administrativo de serviços de alimentação de hospitais e universidades com idades superiores a 55 anos. Os trabalhadores hospitalares foram selecionados na escala de serviço das empresas prestadoras de serviço na área de alimentação.

Os trabalhadores universidades foram selecionados pela lista da Associação Nacional dos Serviços de Alimentação nas Universidades (NACUFS).

A escassez de mão de obra tem retardado o crescimento das industrias alimentícias americanas, contudo o recrutamento e a retenção de trabalhadores mais velhos pode ser um fator para o controle do problema. De acordo com os autores e avaliação de atitudes, a satisfação no trabalho e o engajamento organizacional têm sido demonstrados por rotatividade/aposentadoria dos funcionários. No estudo em pauta, esta relação tornou-se importante por causa das mudanças do modelo demográfico nos Estados Unidos da América, mudanças que têm contribuído para o presente e futuro da escassez de mão de obra nos serviços de alimentação. Não foram encontradas relações estatísticas significativas entre satisfação no trabalho e engajamento, correlacionado com a intenção de aposentar-se ( $v \geq .30$ ). Contudo foi encontrada uma relação estatisticamente pouco significativa entre 
satisfação intrínseca e desejo de retardar a aposentadoria $(\mathrm{v}=.15, \mathrm{p}<.02)$. Os autores destacaram que a rotatividade e a intenção de aposentar-se não são significativamente afetadas pela satisfação no trabalho, bem como por outras variáveis tais como stress, finanças, nível educacional e estado de saúde.

Calbeck, Vaden \& Vaden (1979) avaliaram o nível de satisfação no emprego de nutricionistas hospitalares. Esses resultados foram comparados aos valores de trabalho e satisfação relatados por trabalhadores operacionais de Unidades de Alimentação e Nutrição. Uma análise transversal indicou que nutricionistas estão mais satisfeitos com todos os componentes dos seus empregos, exceto promoção. Eles referiram satisfação com o trabalho em si, com os colegas e com o salário. Em relação à ambição, os nutricionistas foram os que obtiveram scores mais elevados e acreditam que o sucesso é fruto da educação e da especialização, enquanto o outro grupo acredita que o sucesso depende de “conhecer pessoas”. Os trabalhadores operacionais avaliaram que o trabalho era um mal necessário com maior freqüência que os nutricionistas. Ao analisar a satisfação dentre o grupo de nutricionistas, os resultados indicaram que os que referiram maior nível de satisfação são os que possuem algum cargo de chefia, talvez por causa da grande extensão do seu trabalho e da autonomia. A relativa insatisfação com notadas oportunidades de promoção pode ser alguma causa de inquietação na profissão. Os nutricionistas responsáveis por Unidades de Alimentação e Nutrição precisam estar cientes das diferenças de valores de trabalho e satisfação entre nutricionistas e os demais trabalhadores da sua equipe.

Segundo Hogue (1990), os gerentes têm tentado incutir entusiasmo e motivação em empregados de UAN. Sempre foi um desafio engajar trabalhadores e supervisores nas tarefas a serem executadas. Gerentes descrevem que forte autoridade, promessa de recompensas e até punição não funcionam como motivadores. Um gerente pode levar seus empregados a terem entusiasmo, porém logo que se ausente da área de trabalho os funcionários freqüentemente entram em um estado de neutralidade ou reduzem suas atividades. Sugere que os responsáveis pela UAN precisam usar toda ferramenta e recurso disponível para realizar o seu trabalho porque o desenvolvimento de trabalhadores motivados vai ajudar a alcançar um objetivo pleno. As chefias devem fazer o melhor trabalho ao lidar com os empregados como indivíduos e ao entender a dinâmica de um grupo que trabalha em produção. Bons trabalhadores são aqueles cujas vidas são normalmente saudáveis e livres de crises. Deve-se tirar vantagem de programas que trazem 
benefícios para os empregados. Também desenvolver a habilidade de delegar tarefas e responsabilidades e trabalhar com a influência do líder informal em prol do trabalho do grupo. Individualmente as chefias não podem fazer todo o trabalho, porém com um grupo motivado isso é possível. O autor propõe algumas condutas a serem seguidas por chefias produção:

- Buscar compreender a natureza humana;

- Identificar nos trabalhadores as necessidades individuais;

- Olhar para os empregados como pessoas únicas;

- Identificar os objetivos de cada empregado;

- Atuar como instrutores.

O aumento da produtividade associado a motivação e prazer no trabalho são objeto de pesquisa de diferentes áreas. Entretanto, estudo que considera este tema aplicado a nutrição são recente e existem poucas publicações sobre o assunto 


\section{2 - METODOLOGIA}

\section{1 - Sujeitos}

O presente estudo avaliou 70 indivíduos, empregados de uma Unidade de Alimentação e Nutrição (UAN) de um hospital público em Brasília/DF. A UAN hospitalar avaliada é constituída por 118 funcionários distribuídos entre nutricionistas, técnicos administrativos, almoxarifes, copeiros, cozinheiros, padeiros e confeiteiros. Todos os sujeitos selecionados participaram voluntariamente da pesquisa e foram previamente esclarecidos sobre a metodologia empregada. Foram dadas garantias de que a identidade, assim como as respostas obtidas seriam sigilosas.

\section{2 - Critérios de Inclusão}

Responderam ao questionário somente os copeiros, cozinheiros, padeiros, confeiteiros e almoxarifes que estavam em escala de serviço durante o período da coleta de dados. O questionário foi aplicado aos funcionários dos turnos matutinos, vespertino e noturno que estavam escalados para o trabalho durante 3 dias de aplicação do questionário (16 a 18 de dezembro de 2002).

\section{3 - Instrumento}

Utilizou-se como instrumento de coleta de dados, a Escala de Indicadores de Prazer e Sofrimento no Trabalho - EIPST de Mendes (no prelo).

Foi aplicado à amostra um questionário (Anexo A) contendo questões relacionadas ao nível de escolaridade, tempo de trabalho na instituição e no setor, além de questões relacionadas à saúde psíquica.

Essas questões foram apresentadas em uma escala de concordância de 5 pontos, onde 1 corresponde a não concordo até 5 que corresponde a concordo totalmente. Para a análise dos dados, adaptou-se o modelo proposto por Mendes (no prelo), que categorizou as respostas em quatro grupos, sendo dois deles indicadores de prazer e dois indicadores de sofrimento. Os indicadores de prazer são obtidos através do fator gratificação e do fator 
liberdade no trabalho. Os fatores indicadores de sofrimento são obtidos através do fator desgaste e do fator insegurança. Foram incluidas duas questões para análise de valores.

Para a aplicação do questionário foram treinados 3 (três) supervisores (Auxiliares de Nutrição) que repassaram as instruções para o preenchimento da escala aos demais voluntários. O instrumento, preenchido foi depositado em caixa lacrada garantindo o anonimato.

\section{4 - Análise dos dados}

Os dados obtidos foram submetidos ao programa de estatística Excel/97, sendo considerado o nível de significância inferior a 0,05. 


\section{3 -RESULTADOS}

O número de respondentes (70) corresponde a 100\% dos funcionários (copeiros, cozinheiros, padeiros, confeiteiros e almoxarifes) que estavam trabalhando durante a coleta dos dados.

A amostra foi constituída em sua maioria, por mulheres (68\%). A média de idade do grupo avaliado é 39,83 anos (Desvio padrão: \pm 6,44 anos). O Gráfico 1 apresenta a distribuição dos funcionários por idade e sexo.

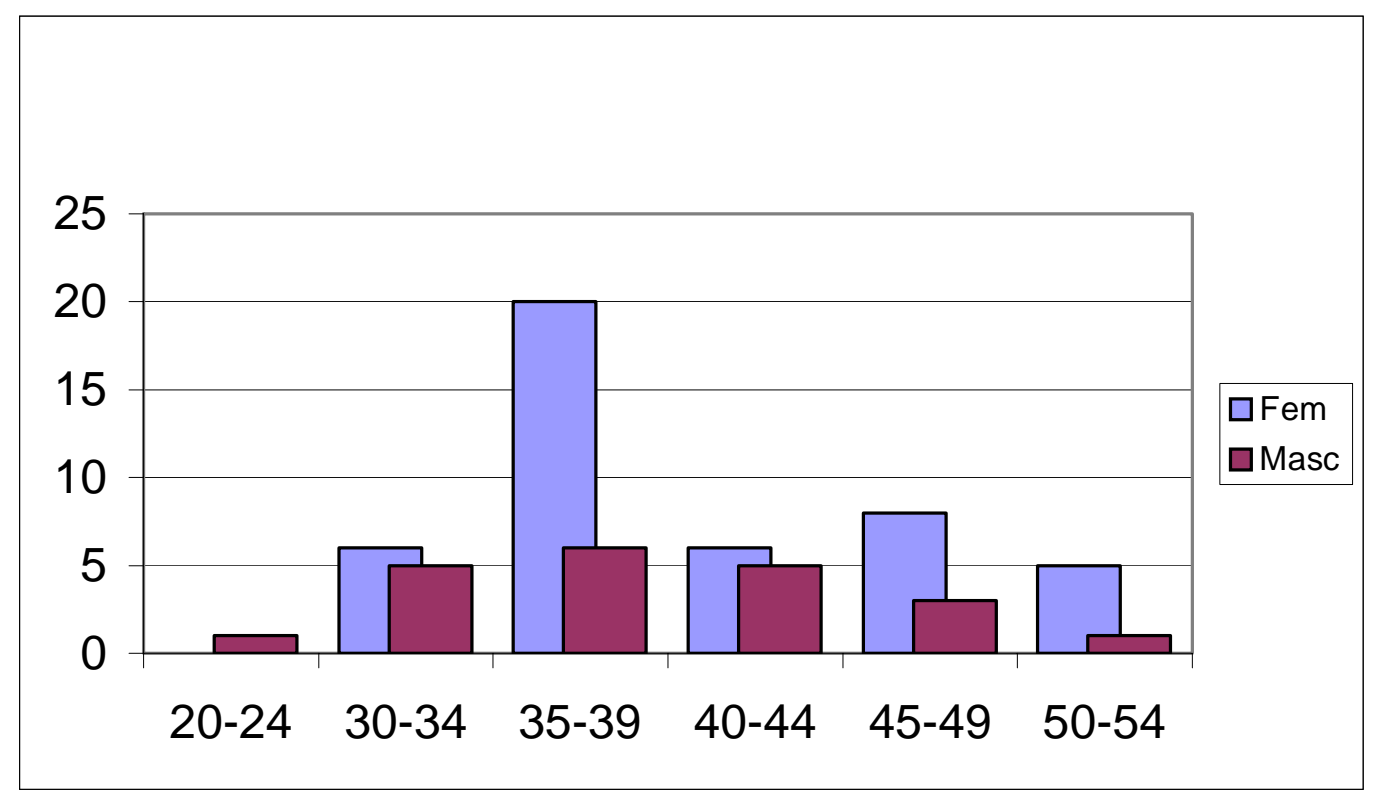

\section{Gráfico 1 - Distribuição dos funcionários por idade e sexo.}

Em relação ao nível de escolaridade, verificou-se que (56,6\%) cursou pelo menos uma série do $2^{\circ}$ grau, enquanto 39,6\% não ultrapassaram o $1^{\circ}$ grau e 3,8\% chegaram ao nível superior. A distribuição da amostra em relação a escolaridade por sexo é apresentada no Gráfico 2. 


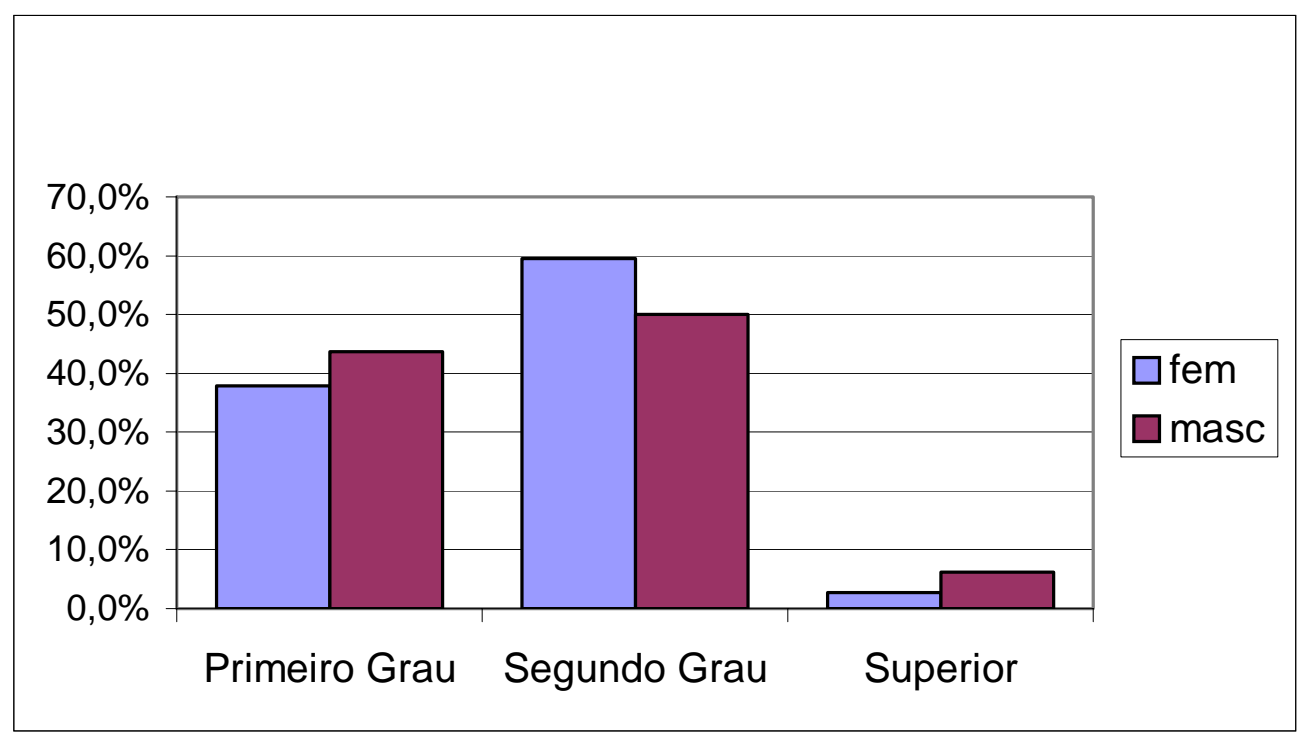

\section{Gráfico 2 - Distribuição da escolaridade da amostra por sexo.}

Avaliou-se o tempo de serviço dos funcionários na instituição. Os dados indicaram que a maioria dos avaliados trabalha na instituição há mais de 6 anos. A tabela 1 descreve o tempo de serviço dos funcionários avaliados.

Tabela 1 - Distribuição da amostra segundo o tempo de serviço na instituição.

\begin{tabular}{lcc}
\hline \multicolumn{1}{c}{ Tempo de serviço na Instituição } & Frequência & Percentual de indivíduos \\
\hline Menos de 2 anos & 11 & $15,7 \%$ \\
De 2 anos a menos de 6 anos & 16 & $22,9 \%$ \\
De 6 anos a menos de 10 anos & 28 & $40,0 \%$ \\
Mais que 10 anos & 15 & $21,4 \%$ \\
Total & 70 & $100,0 \%$ \\
\hline
\end{tabular}

Foi avaliado também o tempo de permanência na função atual. Os resultados indicaram que 47,1\% está na mesma função há 12 meses ou mais. Estes dados serão apresentados na Tabela 2. 
Tabela 2 - Distribuição da amostra segundo o tempo de serviço na função atual.

\begin{tabular}{lcc}
\hline \multicolumn{1}{c}{ Tempo de serviço na Instituição } & Frequência & Percentual de indivíduos \\
\hline Menos de 2 anos & 7 & $10,3 \%$ \\
De 2 anos a menos de 6 anos & 13 & $19,1 \%$ \\
De 6 anos a menos de 10 anos & 16 & $23,5 \%$ \\
Mais que 10 anos & 32 & $47,1 \%$ \\
Total & 68 & $100 \%$ \\
\hline
\end{tabular}

Obs: Dois (2) deixaram de responder a esta pergunta.

Em relação às questões relacionadas à satisfação no trabalho, serão apresentadas inicialmente aquelas categorizadas como indicadores de prazer, através dos fatores de gratificação e liberdade, conforme adaptado do modelo apresentado por Mendes (no prelo) . As questões que avaliaram gratificação indicaram os resultados apresentados nas Tabelas 3 a 12:

Tabela 3 - Resultados obtidos com a pergunta 5: Sinto orgulho do trabalho que realizo

\begin{tabular}{lcc}
\hline $\begin{array}{l}\text { Sinto orgulho do trabalho que } \\
\text { realizo }\end{array}$ & Frequência & Percentual \\
\hline Não concordo & 1 & $1,4 \%$ \\
Concordo pouco & - & - \\
Concordo em parte & 7 & $10,1 \%$ \\
Concordo muito & 14 & $20,3 \%$ \\
Concordo totalmente & 47 & $68,1 \%$ \\
Total & 69 & $100,0 \%$
\end{tabular}

Obs: Um (1) deixou de responder a esta pergunta. 
Tabela 4 - Resultados obtidos com a pergunta 6: Sinto-me reconhecido pelo trabalho que realizo.

\begin{tabular}{|c|c|c|}
\hline $\begin{array}{l}\text { Sinto-me reconhecido } \\
\text { trabalho que realizo }\end{array}$ & Freqüência & Percentual \\
\hline Não concordo & 1 & $1,4 \%$ \\
\hline Concordo pouco & 3 & $4,3 \%$ \\
\hline Concordo em parte & 32 & $46,4 \%$ \\
\hline Concordo muito & 11 & $15,9 \%$ \\
\hline Concordo totalmente & 22 & $31,9 \%$ \\
\hline Total & 69 & $100,0 \%$ \\
\hline
\end{tabular}

Obs: Um (1) deixou de responder a esta pergunta

Tabela 5 - Resultados obtidos com a pergunta 7: Minhas tarefas são significativas para mim.

\begin{tabular}{lcc}
\hline Minhas tarefas são significativas & Frequência & Percentual \\
para mim & & \\
\hline Não concordo & 2 & $3,0 \%$ \\
Concordo pouco & 1 & $1,5 \%$ \\
Concordo em parte & 7 & $10,4 \%$ \\
Concordo muito & 9 & $13,4 \%$ \\
Concordo totalmente & 48 & $71,6 \%$ \\
Total & 67 & $100,0 \%$ \\
\hline
\end{tabular}

Obs: Um (1) deixou de responder a esta pergunta 
Tabela 6 - Resultados obtidos com a pergunta 8: Minhas tarefas são significativas para outras pessoas

\begin{tabular}{lcc}
\hline $\begin{array}{l}\text { Minhas tarefas são significativas } \\
\text { para outras pessoas }\end{array}$ & Frequência & Percentual \\
\hline Não concordo & 3 & $4,5 \%$ \\
Concordo pouco & 1 & $1,5 \%$ \\
Concordo em parte & 12 & $18,2 \%$ \\
Concordo muito & 7 & $10,6 \%$ \\
Concordo totalmente & 43 & $65,2 \%$ \\
Total & 66 & $100,0 \%$ \\
\hline
\end{tabular}

Obs: Quatro (4) deixaram de responder a esta pergunta

Tabela 7 - Resultados obtidos com a pergunta 10: Meu trabalho é compatível com as minhas aspirações profissionais

\begin{tabular}{lcc}
\hline $\begin{array}{l}\text { Meu trabalho é compatível com as } \\
\text { minhas aspirações profissionais }\end{array}$ & Freqüência & Percentual \\
\hline Não concordo & 2 & $2,9 \%$ \\
Concordo pouco & 6 & $8,6 \%$ \\
Concordo em parte & 20 & $28,6 \%$ \\
Concordo muito & 9 & $12,9 \%$ \\
Concordo totalmente & 33 & $47,1 \%$ \\
Total & 70 & $100,0 \%$ \\
\hline
\end{tabular}


Tabela 8 - Resultados obtidos com a pergunta 17: Quando executo minhas tarefas realizo-me profissionalmente

\begin{tabular}{lcc}
\hline $\begin{array}{l}\text { Quando executo minhas tarefas } \\
\text { realizo-me profissionalmente }\end{array}$ & Frequência & Percentual \\
\hline Não concordo & - & - \\
Concordo pouco & 1 & $1,4 \%$ \\
Concordo em parte & 9 & $13,0 \%$ \\
Concordo muito & 11 & $15,9 \%$ \\
Concordo totalmente & 48 & $69,6 \%$ \\
Total & 69 & $100,0 \%$ \\
\hline
\end{tabular}

Obs: Um (1) deixou de responder a esta pergunta

Tabela 9 - Resultados obtidos com a pergunta 19: Sinto-me útil no meu trabalho

\begin{tabular}{lcc}
\hline Sinto-me útil no meu trabalho & Frequência & Percentual \\
\hline Não concordo & - & - \\
Concordo pouco & 4 & $5,9 \%$ \\
Concordo em parte & 2 & $2,9 \%$ \\
Concordo muito & 9 & $13,2 \%$ \\
Concordo totalmente & 53 & $77,9 \%$ \\
Total & 68 & $100,0 \%$
\end{tabular}

Obs: Dois (2) deixaram de responder a esta pergunta 
Tabela 10 - Resultados obtidos com a pergunta 21: Meu salário é compatível com a minha função

\begin{tabular}{lcc}
\hline $\begin{array}{l}\text { Meu salário é compatível com a } \\
\text { minha função }\end{array}$ & Freqüência & Percentual \\
\hline Não concordo & 5 & $7,1 \%$ \\
Concordo pouco & 3 & $4,3 \%$ \\
Concordo em parte & 16 & $22,9 \%$ \\
Concordo muito & 16 & $22,9 \%$ \\
Concordo totalmente & 30 & $42,9 \%$ \\
Total & 70 & $100,0 \%$ \\
\hline
\end{tabular}

Tabela 11 - Resultados obtidos com a pergunta 26: Sinto-me produtivo no meu trabalho.

\begin{tabular}{lccc}
\hline $\begin{array}{l}\text { Sinto-me produtivo no meu } \\
\text { trabalho }\end{array}$ & Freqüência & Percentual \\
\hline Não concordo & 1 & $1,4 \%$ \\
Concordo pouco & - & - \\
Concordo em parte & 4 & $5,7 \%$ \\
Concordo muito & 16 & $22,9 \%$ \\
Concordo totalmente & 49 & $70,0 \%$ \\
Total & 70 & $100,0 \%$ \\
\hline
\end{tabular}


Tabela 12 - Resultados obtidos com a pergunta 27: Meu trabalho é importante para a organização.

\begin{tabular}{lcc}
\hline $\begin{array}{l}\text { Meu trabalho é importante para a } \\
\text { organização }\end{array}$ & Freqüência & Percentual \\
\hline Não concordo & 1 & $1,4 \%$ \\
Concordo pouco & - & - \\
Concordo em parte & 1 & $1,4 \%$ \\
Concordo muito & 11 & $15,7 \%$ \\
Concordo totalmente & 57 & $81,4 \%$ \\
Total & 70 & $100,0 \%$ \\
\hline
\end{tabular}

Os resultados obtidos pelas questões que avaliaram a liberdade serão apresentados nas tabelas 13 a 16.

Tabela 13 - Resultados obtidos com a pergunta 03: Tenho liberdade na organização do meu trabalho da forma que quero

\begin{tabular}{lcc}
\hline $\begin{array}{l}\text { Tenho liberdade na organização } \\
\text { do meu trabalho da forma que }\end{array}$ & Frequência & Percentual \\
quero & & \\
\hline Não concordo & 8 & $11,8 \%$ \\
Concordo pouco & 17 & $25,0 \%$ \\
Concordo em parte & 29 & $42,6 \%$ \\
Concordo muito & 3 & $4,4 \%$ \\
Concordo totalmente & 11 & $16,2 \%$ \\
Total & 68 & $100,0 \%$
\end{tabular}

Obs: Dois (2) deixaram de responder a esta pergunta 
Tabela 14 - Resultados obtidos com a pergunta 12: Sinto meus colegas solidários comigo.

\begin{tabular}{lcc}
\hline $\begin{array}{l}\text { Sinto meus colegas } \\
\text { comigo }\end{array}$ & Frequência & Percentual \\
\hline Não concordo & 4 & $5,7 \%$ \\
Concordo pouco & 12 & $17,1 \%$ \\
Concordo em parte & 30 & $42,9 \%$ \\
Concordo muito & 8 & $11,4 \%$ \\
Concordo totalmente & 16 & $22,9 \%$ \\
Total & 70 & $100,0 \%$ \\
\hline
\end{tabular}

Tabela 15 - Resultados obtidos com a pergunta 15: Sinto o reconhecimento da minha chefia pelo trabalho que realizo

\begin{tabular}{lcc}
\hline $\begin{array}{l}\text { Sinto o reconhecimento da minha } \\
\text { chefia pelo trabalho que realizo }\end{array}$ & Freqüência & Percentual \\
\hline Não concordo & - & - \\
Concordo pouco & 6 & $8,7 \%$ \\
Concordo em parte & 20 & $29,0 \%$ \\
Concordo muito & 17 & $24,6 \%$ \\
Concordo totalmente & 26 & $37,7 \%$ \\
Total & 69 & $100,0 \%$ \\
\hline
\end{tabular}

Obs: Um (1) deixou de responder a esta pergunta 
Tabela 16 - Resultados obtidos com a pergunta 18: Tenho liberdade para dizer o que eu penso sobre o meu trabalho.

\begin{tabular}{lcc}
\hline $\begin{array}{l}\text { Tenho liberdade para dizer o que } \\
\text { eu penso sobre o meu trabalho }\end{array}$ & Frequência & Percentual \\
\hline Não concordo & 10 & $15,4 \%$ \\
Concordo pouco & 7 & $10,8 \%$ \\
Concordo em parte & 26 & $40,0 \%$ \\
Concordo muito & 7 & $10,8 \%$ \\
Concordo totalmente & 15 & $23,1 \%$ \\
Total & 65 & $100,0 \%$ \\
\hline
\end{tabular}

Obs: Cinco (5) deixaram de responder a esta pergunta

Em relação aos resultados obtidos nas questões que avaliam o sofrimento associado ao trabalho, serão apresentadas nos fatores de desgosto e insegurança, conforme adaptado do modelo apresentado por Mendes (no prelo). As questões que avaliaram desgosto indicaram os resultados apresentados nas Tabelas 17 a 23:

Tabela 17 - Resultados obtidos com a pergunta 01: Meu Trabalho é cansativo

\begin{tabular}{lcc}
\hline Meu trabalho é cansativo & Freqüência & Percentual \\
\hline Não concordo & 10 & $14,5 \%$ \\
Concordo pouco & 9 & $13,0 \%$ \\
Concordo em parte & 34 & $49,3 \%$ \\
Concordo muito & 13 & $18,8 \%$ \\
Concordo totalmente & 3 & $4,3 \%$ \\
Total & 69 & $100 \%$ \\
\hline
\end{tabular}

Obs: Um (1) deixou de responder a esta pergunta 
Tabela 18 - Resultados obtidos com a pergunta 04: Sinto frustração no meu trabalho.

\begin{tabular}{lcc}
\hline Sinto frustação no meu trabalho & Freqüência & Percentual \\
\hline Não concordo & 50 & $72,5 \%$ \\
Concordo pouco & 8 & $11,6 \%$ \\
Concordo em parte & 6 & $8,7 \%$ \\
Concordo muito & 1 & $1,4 \%$ \\
Concordo totalmente & 4 & $5,8 \%$ \\
Total & 69 & $100,0 \%$ \\
\hline
\end{tabular}

Obs: Um (1) deixou de responder a esta pergunta

Tabela 19 - Resultados obtidos com a pergunta 11: Meu trabalho me causa estresse.

\begin{tabular}{lcc}
\hline Meu trabalho me causa estresse & Freqüência & Percentual \\
\hline Não concordo & 24 & $34,3 \%$ \\
Concordo pouco & 11 & $15,7 \%$ \\
Concordo em parte & 23 & $32,9 \%$ \\
Concordo muito & 6 & $8,6 \%$ \\
Concordo totalmente & 6 & $8,6 \%$ \\
Total & 70 & $100,0 \%$ \\
\hline
\end{tabular}


Tabela 20 - Resultados obtidos com a pergunta 14: Sinto-me sobrecarregado no meu trabalho.

\begin{tabular}{lcc}
\hline $\begin{array}{l}\text { Sinto-me sobrecarregado no meu } \\
\text { trabalho }\end{array}$ & Freqüência & Percentual \\
\hline Não concordo & 19 & $27,9 \%$ \\
Concordo pouco & 10 & $14,7 \%$ \\
Concordo em parte & 26 & $38,2 \%$ \\
Concordo muito & 6 & $8,8 \%$ \\
Concordo totalmente & 7 & $10,3 \%$ \\
Total & 68 & $100,0 \%$ \\
\hline
\end{tabular}

Obs: Dois (2) deixaram de responder a esta pergunta

Tabela 21: Resultados obtidos com a pergunta 20: Tenho-me sentido adormecido com relação à minha carreira profissional

\begin{tabular}{lcc}
\hline Tenho-me sentido adormecido & Freqüência & Percentual \\
com realcão à minha carreira & & \\
profissional & & \\
\hline Não concordo & 25 & $36,2 \%$ \\
Concordo pouco & 3 & $4,3 \%$ \\
Concordo em parte & 27 & $39,1 \%$ \\
Concordo muito & 4 & $5,8 \%$ \\
Concordo totalmente & 10 & $14,5 \%$ \\
Total & 69 & $100,0 \%$
\end{tabular}

Obs: Um (1) deixou de responder a esta pergunta 
Tabela 22 - Resultados obtidos com a pergunta 23: Meu trabalho me causa sofrimento

\begin{tabular}{lcc}
\hline Meu trabalho me causa sofrimento & Freqüência & Percentual \\
\hline Não concordo & 57 & $82,6 \%$ \\
Concordo pouco & 5 & $7,2 \%$ \\
Concordo em parte & 5 & $7,2 \%$ \\
Concordo muito & - & - \\
Concordo totalmente & 2 & $2,9 \%$ \\
Total & 69 & $100,0 \%$
\end{tabular}

Obs: Um (1) deixou de responder a esta pergunta

Tabela 23 - Resultados obtidos com a pergunta 25: Sinto-me desmotivado em relação ao meu trabalho.

\begin{tabular}{lcc}
\hline $\begin{array}{l}\text { Sinto-me desmotivado em relação } \\
\text { ao meu trabalho }\end{array}$ & Freqüência & Percentual \\
\hline Não concordo & 42 & $61,8 \%$ \\
Concordo pouco & 8 & $11,8 \%$ \\
Concordo em parte & 13 & $19,1 \%$ \\
Concordo muito & 1 & $1,5 \%$ \\
Concordo totalmente & 4 & $5,9 \%$ \\
Total & 68 & $100,0 \%$ \\
\hline
\end{tabular}

Obs: Dois (2) deixaram de responder a esta pergunta 
Os resultados obtidos pelas questões que avaliaram insegurança serão apresentados nas tabelas 24 a 28

Tabela 24 - Resultados obtidos com a pergunta 02: Sinto-me inseguro quando meu trabalho não corresponde às expectativas da empresa.

\begin{tabular}{lcc}
\hline $\begin{array}{l}\text { Sinto-me inseguro quando meu } \\
\text { trabalho não corresponde às } \\
\text { expectativas da empresa. }\end{array}$ & Freqüência & Percentual \\
\hline Não concordo & 23 & \\
Concordo pouco & 11 & $33,8 \%$ \\
Concordo em parte & 13 & $16,2 \%$ \\
Concordo muito & 8 & $19,1 \%$ \\
Concordo totalmente & 13 & $11,8 \%$ \\
Total & 68 & $19,1 \%$ \\
\hline
\end{tabular}

Obs: Dois (2) deixaram de responder a esta pergunta

Tabela 25 - Resultados obtidos com a pergunta 09: Tenho receio de ser demitido ao cometer erros.

\begin{tabular}{lll}
\hline Tenho receio de ser demitido ao & Freqüência & Percentual
\end{tabular}

cometer erros

\begin{tabular}{lcc}
\hline Não concordo & 17 & $25,0 \%$ \\
Concordo pouco & 6 & $8,8 \%$ \\
Concordo em parte & 22 & $32,4 \%$ \\
Concordo muito & 3 & $4,4 \%$ \\
Concordo totalmente & 20 & $29,4 \%$ \\
Total & 68 & $100,0 \%$
\end{tabular}

Obs: Dois (2) deixaram de responder a esta pergunta 
Tabela 26 - Resultados obtidos com a pergunta 13: Receio não ser capaz de executar minhas tarefas no prazo estipulado.

\begin{tabular}{lcc}
\hline $\begin{array}{l}\text { Receio não ser capaz de executar } \\
\text { minhas tarefas no prazo estipulado }\end{array}$ & Freqüência & Percentual \\
\hline Não concordo & 40 & $61,5 \%$ \\
Concordo pouco & 5 & $7,7 \%$ \\
Concordo em parte & 9 & $13,8 \%$ \\
Concordo muito & 6 & $9,2 \%$ \\
Concordo totalmente & 5 & $7,7 \%$ \\
Total & 65 & $100,0 \%$ \\
\hline
\end{tabular}

Obs: Cinco (5) deixaram de responder a esta pergunta

Tabela 27 - Resultados obtidos com a pergunta 29: Sinto-me pressionado no meu trabalho

\begin{tabular}{lcc}
\hline $\begin{array}{l}\text { Sinto-me pressionado no meu } \\
\text { trabalho }\end{array}$ & Freqüência & Percentual \\
\hline Não concordo & 29 & $42,0 \%$ \\
Concordo pouco & 12 & $17,4 \%$ \\
Concordo em parte & 17 & $24,6 \%$ \\
Concordo muito & 6 & $8,7 \%$ \\
Concordo totalmente & 5 & $7,2 \%$ \\
Total & 69 & $100,0 \%$ \\
\hline
\end{tabular}

Obs: Um (1) deixou de responder a esta pergunta 
Tabela 28: Resultados obtidos com a pergunta 24: Permaneço neste trabalho por falta de outra oportunidade.

\begin{tabular}{lcc}
\hline $\begin{array}{l}\text { Permaneço neste trabalho por falta } \\
\text { de outra oportunidade }\end{array}$ & Freqüência & Percentual \\
\hline Não concordo & 45 & $65,22 \%$ \\
Concordo pouco & 5 & $7,25 \%$ \\
Concordo em parte & 11 & $15,94 \%$ \\
Concordo muito & 5 & $7,25 \%$ \\
Concordo totalmente & 3 & $4,35 \%$ \\
Total & 69 & $100,0 \%$ \\
\hline
\end{tabular}

Obs: Um (1) deixou de responder a esta pergunta 
Os resultados das questões que avaliam valores são apresentadas nas tabelas 29 e 30 . Sendo, que esta última pedia-se aos inqueridos que escalonassem por ordem de importância, o que eles consideravam mais importante nos seus empregos.

Tabela 29 - Resultados obtidos com a pergunta 22: A prática religiosa é importante na vida.

A prática religiosa é importante na Freqüência

Percentual

vida

Não concordo

1

$1,4 \%$

Concordo pouco

1

$1,4 \%$

Concordo em parte

3

$4,3 \%$

Concordo muito

Concordo totalmente

64

$92,8 \%$

Total

69

$100,0 \%$

Obs: Um (1) deixou de responder a esta pergunta

Tabela 30 - Variáveis consideradas mais importantes em relação ao emprego.

\begin{tabular}{lcccc}
\hline \multicolumn{1}{c}{ VARIÁVEL } & Média & Desvio & Mediana & Moda \\
\hline Salário & 2,98 & 1,35 & 2 & 2 \\
Respeito adquirido & 2,38 & 1,42 & 2 & 1 \\
Segurança & 3,32 & 1,16 & 4 & 4 \\
Realização pessoal & 2,98 & 1,56 & 3 & 1 \\
Sentir-se parte de um grupo & 3,68 & 1,55 & 4 & 5
\end{tabular}

Nota 1: Apenas 54 inquiridos (77\% do total) responderam corretamente à pergunta.

Nota 2: Os pesos a atribuir variaram de 1 a 5 onde a ordem de importância está de forma crescente, isto é, 1 é a mais importante e 5 a menos importante. 
O item "respeito adquirido” constituiu a variável mais importante de acordo com as três medidas estatísticas de posição (média, mediana e moda). O "salário" foi a segunda variável mais cotada, ao passo que o item "segurança” e a variável "realização pessoal" obtiveram valores iguais para a média, situando-se no meio da distribuição. Esses dados também são apresentados no Gráfico 03

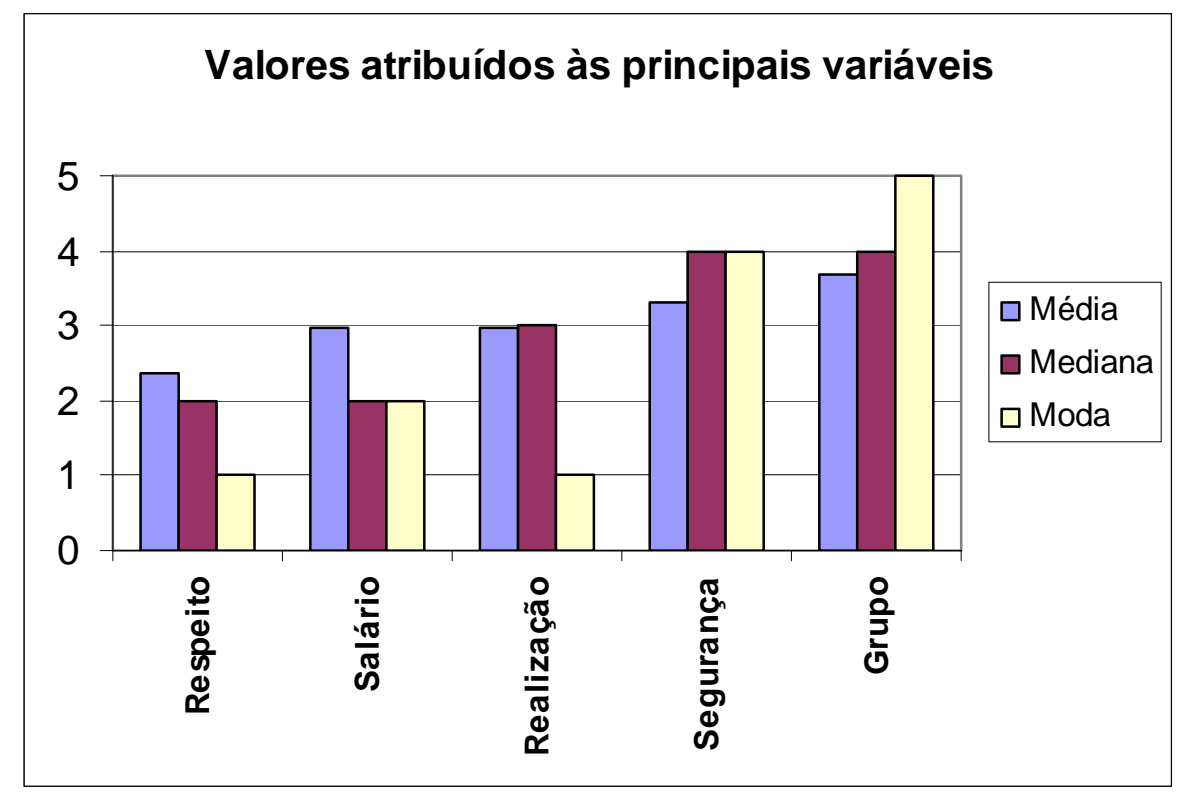

Gráfico 03 - Valores atribuídos às principais variáveis 
Tabela 31 - Comparação dos funcionários satisfeitos com o valor máximo possível

\begin{tabular}{|c|c|c|c|c|c|}
\hline GRUPO & Pergunta & Tabela & Satisfeitos & Total na amostra & $\%$ \\
\hline \multicolumn{6}{|c|}{ INDICADORES POSITIVOS } \\
\hline \multirow[t]{11}{*}{ Gratificação } & 5 & 3 & 61 & 69 & $88,4 \%$ \\
\hline & 6 & 4 & 33 & 69 & $47,8 \%$ \\
\hline & 7 & 5 & 57 & 67 & $85,1 \%$ \\
\hline & 8 & 6 & 50 & 66 & $75,8 \%$ \\
\hline & 10 & 7 & 42 & 76 & $55,3 \%$ \\
\hline & 17 & 8 & 59 & 69 & $85,5 \%$ \\
\hline & 19 & 9 & 62 & 68 & $91,2 \%$ \\
\hline & 21 & 10 & 46 & 70 & $65,7 \%$ \\
\hline & 26 & 11 & 65 & 70 & $92,9 \%$ \\
\hline & 27 & 12 & 68 & 70 & $97,1 \%$ \\
\hline & & & 543 & 694 & $78,2 \%$ \\
\hline \multirow[t]{5}{*}{ Liberdade } & 3 & 13 & 14 & 68 & $20,6 \%$ \\
\hline & 12 & 14 & 24 & 70 & $34,3 \%$ \\
\hline & 15 & 15 & 43 & 69 & $62,3 \%$ \\
\hline & 18 & 16 & 22 & 65 & $33,8 \%$ \\
\hline & & & 103 & 272 & $37,9 \%$ \\
\hline \multicolumn{6}{|c|}{ INDICADORES NEGATIVOS } \\
\hline \multirow[t]{8}{*}{ Desgosto } & 1 & 17 & 53 & 69 & $76,8 \%$ \\
\hline & 4 & 18 & 64 & 69 & $92,8 \%$ \\
\hline & 11 & 19 & 58 & 70 & $82,9 \%$ \\
\hline & 14 & 20 & 55 & 68 & $80,9 \%$ \\
\hline & 20 & 21 & 55 & 69 & $79,7 \%$ \\
\hline & 23 & 22 & 67 & 69 & $97,1 \%$ \\
\hline & 25 & 23 & 63 & 68 & $92,6 \%$ \\
\hline & & & 415 & 482 & $86,1 \%$ \\
\hline \multirow[t]{6}{*}{ Insegurança } & 2 & 24 & 47 & 68 & $69,1 \%$ \\
\hline & 9 & 25 & 45 & 68 & $66,2 \%$ \\
\hline & 13 & 26 & 54 & 65 & $83,1 \%$ \\
\hline & 16 & 27 & 58 & 69 & $84,1 \%$ \\
\hline & 24 & 28 & 61 & 69 & $88,4 \%$ \\
\hline & & & 265 & 339 & $78,2 \%$ \\
\hline \multicolumn{6}{|c|}{ INDICADOR DE “VALOR” } \\
\hline Religião & 22 & 29 & 67 & 69 & $97,1 \%$ \\
\hline
\end{tabular}


$\mathrm{Na}$ Tabela 31 encontram-se os resultados obtidos a todas as respostas tendo se classificado de acordo com o tipo de indicadores. Assim temos:

- gratificação;

- liberdade;

- desgosto e

- insegurança "valor".

A pergunta sobre religião não foi incluída em nenhum dos grupos acima, pois avalia

Os indicadores de "gratificação"e "liberdade"foram considerados como POSITIVOS.

Os indicadores de “desgosto"e “insegurança”foram considerados como NEGATIVOS.

Nos indicadores positivo, consideraram-se como "satisfeitos" os funcionários que responderam "não concordo", "concordo pouco" ou "concordo em parte".

A comparação do número de funcionários satisfeitos real com o número total que seriam obtidos se todos estivessem plenamente satisfeitos, revelou que: nos itens "gratificação", “desgosto"e "insegurança” não existem diferenças significativas entre o número real de funcionários satisfeitos e o número total possível. Assim podemos concluir, quanto a esses itens, que o pessoal do setor se sente satisfeito e realizado no seu trabalho. No entanto, seria preciso investigar melhor as perguntas 6 e 10 do grupo "gratificação"onde se encontram as maiores diferenças entre o número real de pessoas satisfeitas e o numero total que seria possível se todos estivessem satisfeitos.

Quanto ao grupo “liberdade”o padrão encontrado nas respostas revelam uma diferença muito significativa entre o que seria ideal e a realidade; os resultados sugerem um elevado grau de descontentamento.

A comparação entre os valores encontrados e os valores ideais, foi realizada pelo teste de qui-quadrado, cujos resultados se apresentam na seguinte tabela:

Tabela 32 - Teste de Qui-Quadrado

\begin{tabular}{lrr}
\hline \multicolumn{1}{c}{ INDICADORES } & Qui-quadrado & P \\
\hline Gratificação & 12,24 & 0,14 \\
Liberdade & 11,54 & 0,009 \\
Desgosto & 1,59 & 0,95 \\
Insegurança & 1,94 & 0,75 \\
\hline
\end{tabular}




\section{4 - DISCUSSÃO}

O presente estudo teve como objetivo identificar o grau de satisfação dos funcionários de uma UAN por meio da aplicação de uma escala de prazer-sofrimento no trabalho. Os dados serão discutidos a partir das questões que avaliaram características da amostra e dos indicadores de prazer-sofrimento.

\section{1 - Características da amostra:}

A amostra do estudo foi constituída, principalmente, por mulheres. A faixa etária média encontrada foi de é 39,83 anos (Desvio padrão: \pm 6,44 anos). A escolaridade média do grupo é o $2^{\circ}$ grau. Quarenta por cento dos servidores trabalham na instituição há mais de seis e há menos de dez anos. Tais características são semelhantes às descritas por Proença (1996) ao avaliar as condições de saúde de 14 operadores de UAN, com média de idade 39 anos e 5,08 anos como o tempo de serviço na instituição. Em relação à escolaridade os estudos avaliados não descreveram o nível de instrução formal da sua população.

A avaliação do tempo de serviço dos funcionários que constituíram a amostra deste estudo indicou baixa rotatividade, visto que 61,4\% trabalham na instituição há mais de seis anos. Martin \& Vaden (1978) ao avaliarem o efeito do tempo de trabalho sobre a satisfação dos funcionários de uma UAN hospitalar, concluíram que trabalhadores que estavam na instituição há menos de seis meses e há mais de três anos foram os funcionários com maiores índices de satisfação.

Quando analisados, nesta pesquisa, os dados referentes a tempo de trabalho no setor, cerca de 47,1\% estavam no setor há 12 meses ou mais. Esse dado merece atenção especial, uma vez que Dejours (1992) afirma que o trabalho repetitivo cria insatisfação e pode produzir descompensações mentais ou doenças somáticas. Sneed e Herman (1990) descreveram que a variedade de tarefas executadas, assim como o feedback em relação a tais tarefas são as características que melhor se relacionam com a satisfação no trabalho e com o desenvolvimento do compromisso com a instituição. A variedade pode ser aumentada com a rotatividade das funções e com o constante treinamento, estratégias que aumentarão não só a variedade na tarefa, mas também a produtividade da UAN, uma vez que mais de um funcionário estará familiarizado com determinada função. O feedback para 
os trabalhadores sobre como estão sendo realizadas suas tarefas aumenta a possibilidade de reavaliar e replanejar suas condutas.

\section{2 - Os indicadores de prazer-sofrimento na UAN:}

Conforme apresentado por Mendes (no prelo) os indicadores de prazer são constituídos pelos fatores gratificação e liberdade, enquanto os indicadores de sofrimento são definidos pelos fatores de desgosto e insegurança. A freqüência de respostas do tipo Concordo totalmente obtidos nos indicadores gratificação e liberdade foram significativamente altos quando comparados aos indicadores de sofrimento, sugerindo que a amostra estudada apresenta alto grau de prazer no trabalho.

Indicadores como sentir orgulho do trabalho realizado, considerar a tarefa importante para ele e para a organização, sentir-se produtivo, identificar-se com um trabalho que atende às suas aspirações profissionais, ter liberdade no trabalho e reconhecimento da chefia contribuem para justificar o nível de satisfação encontrado na amostra. Segundo Dejours (1992) a congruência entre os desejos da instituição e as expectativas do trabalhador são fatores que determinam a prevalência do sentimento de prazer no trabalho. A sensação do respeito adquirido, bem como a realização pessoal, identidade e sensação de que faz parte de um grupo são indicadores de satisfação e estimulam o trabalhador a dar a sua contribuição máxima à organização (Dejours, 1992; Mendes , no prelo; Leite, 2002).

Nunes (2000) destaca que o clima organizacional é o reflexo de um processo de interação dinâmica que envolve as condições de trabalho, interação entre chefes e empregados, levando ao aumento da satisfação e da produtividade. A partir disso, pode-se considerar que outro fator que contribui para justificar sentimento de prazer o é o fato de que população estudada tem a possibilidade de acompanhar o produto final do seu trabalho, uma vez que são funcionários de uma UAN hospitalar com freqüência, mantém contato com os usuários saudáveis ou pacientes da instituição. Segundo Morrone (2001) atividades com possibilidade de visualização dos resultados do trabalho exercem papel significativo na vivência do prazer. Além disso, o hospital da UAN pesquisada goza de prestígio e respeito frente à sociedade, sendo parte da política organizacional despertar nos seus funcionários o orgulho de fazer parte desta instituição. 
A satisfação com o salário, estímulos freqüentes da chefia imediata, bem como da direção também configuraram como estratégias adotadas com o objetivo de manter o nível de satisfação dos trabalhadores neste setor. Provavelmente, a amostra estudada esteja sensível a tais estratégias, pois ao investigar o que os empregados consideravam mais importante em relação ao emprego os resultados indicaram que o item respeito adquirido é o mais importante, seguido pelo item salário. 


\section{CONSIDERAÇÕES FINAIS}

Os resultados obtidos indicaram que a amostra analisada é constituída na sua maioria por mulheres, com média de idade de 39 anos. O grupo analisado não se sente inseguro, frustrado ou desmotivado em relação ao trabalho. Os funcionários relataram ter orgulho do seu trabalho e consideram sua tarefa importante para si próprio e para a instituição, sente-se realizado e considera o respeito adquirido o item mais importante do seu trabalho, seguido do item salário.

As estratégias adotadas por esta UAN parecem ter sido eficazes uma vez que os resultados indicaram que os indivíduos apresentavam elevado grau de satisfação no trabalho, quando submetido a uma escala de avaliação de prazer-sofrimento, com predomínio dos indicadores de prazer.

Faz-se necessário o desenvolvimento de mais pesquisas sobre satisfação no trabalho de operadores de UAN, com vistas a treinamento de pessoal e desenvolvimento de estratégias e habilidades que garantam condições, para a estruturação psíquica dos operadores e para vivenciar o prazer no trabalho. Ações dos coordenadores de equipes podem atuar de forma direcionada à melhoria de qualidade do trabalho realizado e sobretudo à qualidade de vida do empregado. 
ANEXO

O questionário e os dados serão mantidos em sigilo e a sua opinião "verdadeira" será de fundamental importância para o estudo.

DADOS PESSOAIS

Sexo ( ) M

Escolaridade:

( )F Idade:

Setor:

Função:

Há quanto tempo trabalha na instituição?

Menos de 2 anos ( )

Entre 2 a 6 anos ( )

Entre 6 a 10 anos

Mais de 10 anos ( )

Há quanto tempo trabalha neste setor?

Menos de 2 meses ( )

Entre 6 a 12 meses ( )

Entre 2 a 6 meses ( )

Mais de 1 ano

Você tem alguma atividade de lazer regular?

( ) Sim

( )Não

Leia as frases abaixo, analisando cada uma de acordo o que você sente no dia-a-dia do trabalho. Marque, utilizando a escala abaixo, o número que melhor corresponde a sua avaliação.

\begin{tabular}{|c|c|c|c|c|}
\hline 1 & 2 & 3 & 4 & 5 \\
Não Concordo & Concordo Pouco & Concordo em Parte & Concordo Muito & Concordo Totalmente \\
\hline
\end{tabular}

\begin{tabular}{|c|c|c|c|c|c|}
\hline 1. Meu trabalho é cansativo. & 1 & 2 & 3 & 4 & 5 \\
\hline $\begin{array}{l}\text { 2. Sinto-me inseguro quando o meu trabalho não corresponde às } \\
\text { expectativas da empresa. }\end{array}$ & 1 & 2 & 3 & 4 & 5 \\
\hline 3. Tenho liberdade para organizar meu trabalho da forma que quero. & 1 & 2 & 3 & 4 & 5 \\
\hline 4. Sinto frustrações com meu trabalho. & 1 & 2 & 3 & 4 & 5 \\
\hline 5. Sinto orgulho do trabalho que realizo. & 1 & 2 & 3 & 4 & 5 \\
\hline 6. Sinto-me reconhecido pelo trabalho que realizo. & 1 & 2 & 3 & 4 & 5 \\
\hline 7. Minhas tarefas são significativas para mim. & 1 & 2 & 3 & 4 & 5 \\
\hline 8. Minhas tarefas são significativas para outras pessoas. & 1 & 2 & 3 & 4 & 5 \\
\hline 9. Tenho receio de ser demitido ao cometer erros. & 1 & 2 & 3 & 4 & 5 \\
\hline 10. Meu trabalho é compatível com as minhas aspirações profis & 1 & 2 & 3 & 4 & 5 \\
\hline
\end{tabular}




\begin{tabular}{|c|c|c|c|c|c|}
\hline 11. Meu trabalho me causa estresse. & 1 & 2 & 3 & 4 & 5 \\
\hline 12. Sinto meus colegas solidários comigo. & 1 & 2 & 3 & 4 & 5 \\
\hline 13. Receio não ser capaz de executar minhas tarefas no prazo estipulado. & 1 & 2 & 3 & 4 & 5 \\
\hline 14. Sinto-me sobrecarregado no meu trabalho. & 1 & 2 & 3 & 4 & 5 \\
\hline 15. Sinto o reconhecimento da minha chefia pelo trabalho que realizo. & 1 & 2 & 3 & 4 & 5 \\
\hline 16. Sinto-me pressionado no meu trabalho. & 1 & 2 & 3 & 4 & 5 \\
\hline 17. Quando executo minhas tarefas realizo-me profissionalmente. & 1 & 2 & 3 & 4 & 5 \\
\hline 18. Tenho liberdade para dizer o que penso sobre meu trabalho. & 1 & 2 & 3 & 4 & 5 \\
\hline 19. Sinto-me útil no meu trabalho & 1 & 2 & 3 & 4 & 5 \\
\hline $\begin{array}{l}\text { 20. Tenho me sentido adormecido com relação à minha carreira } \\
\text { profissional }\end{array}$ & 1 & 2 & 3 & 4 & 5 \\
\hline 21. Meu salário é compatível com a minha função. & 1 & 2 & 3 & 4 & 5 \\
\hline 22. A prática religiosa é importante na vida. & 1 & 2 & 3 & 4 & 5 \\
\hline 23. Meu trabalho me causa sofrimento. & 1 & 2 & 3 & 4 & 5 \\
\hline 24. Permaneço neste trabalho por falta de outra oportunidade. & 1 & 2 & 3 & 4 & 5 \\
\hline 25. Sinto-me desmotivado em relação ao meu trabalho. & 1 & 2 & 3 & 4 & 5 \\
\hline 26. Sinto-me produtivo no meu trabalho. & 1 & 2 & 3 & 4 & 5 \\
\hline 27. Meu trabalho é importante para a organização. & 1 & 2 & 3 & 4 & 5 \\
\hline
\end{tabular}

Enumere de 01 a 06 o que você considera mais importante no seu emprego?

salário

respeito adquirido

segurança

realização pessoal

sentir-se parte de um grupo.

outro qual?

Gostaria de declarar mais alguma coisa que julgue importante sobre o seu trabalho? 


\section{REFERÊNCIAS BIBLIOGRÁFICAS}

- CALBECK, D. C.; VADEN, A. G.; VADEN, R. E. Work-related values and satisfactions. Journal of the American Dietetic Association. Manhattan., v. 75, p. 434-440, oct . 1979.

- DEJOURS, C. (1999a) Conferências Brasileiras: identidade, reconhecimento e transgressão no trabalho, (ACF Reis, Trad.) São Paulo, Fundap: EAE S/FGV.

- DEJOURS, C. (1997/1999) O Fator Humano, (MIS Betiol, Trad.) Rio de Janeiro: Editora FGV.

- DEJOURS, C.; ABDOUCHELI, E. e Jayet, C. (1994) Psicodinâmica do trabalho: contribuições da escola dejouriana à análise da relação prazer, sofrimento e trabalho. (Betiol, MLS (Coord). São Paulo: Atlas.

- DEJOURS, C. (1980/1992) A Loucura do Trabalho: estudo de psicopatologia do trabalho. (AI Paraguay e LL Ferreira, Trad.) São Paulo: Cortez.

- DEMICCO, F. J.; OLSEN M. D. The relationship pf no work satisfaction and organizational commitment to retirement intention. Journal of the American Dietetic Association, Blacksburg, v. 88, n. 8. p. 921-927, aug.1988.

- HOGUE, M. A. How to Develop a Creative and Self-Motivated Work Team. Hospital Food and Nutrition Focus, Boston, v. 6, n. 5, p. 1-4, Jan. 1990.

- LEITE, G.M. de F. Fatores de Satisfação e Insatisfação no trabalho em diversas categorias de trabalhadores. Uberlândia, 2002. 186p. Dissertação (Mestrado em Administração). Centro Universitário do Triângulo.

- MASLOW, A.H. Maslow no Gerenciamento, Rio de Janeiro. Quality mark, 2000.

- MASLOW, A.H. Motivation and personality, New York, Harper and, Row, 1970.

- MATOS, C.H. de. O trabalho na produção de refeições pode alterar o estado nutricional dos operadores.Nutrição em Pauta, São Paulo, ano 9, n. 49, p.26 jul/ago.2001.

- MENDES, A.M. Validação de uma escala de indicadores de prazer-sofrimento no trabalho, Brasília. Pesquisa Instituto de Psicologia. Universidade de Brasília, no prelo.

- MORRONE, C.F. Só para não ficar desempregado. Resignificando o sofrimento psíquico no trabalho: estudo com trabalhadores em atividades informais. Brasília, 2001. 129p. Dissertação (Mestrado em Psicologia) - Instituto de Psicologia, Universidade de Brasília.

- NUNES, L.G.N. Improvement Through Motivation and Organizational Climáte Análysis: an application on a brazilian hospital. Maastricht, 2000. 49p. Dissertação (Masters of Business Administration-MBA.) Maastricht School of Management. 
- PROENÇA, R.P. da C. Inovações tecnológicas na produção de refeições: Conceitos e aplicações básicas,Higiene Alimentar, Florianópolis, v. 13, n.63, p. 24-30, jul./ago. 1999.

- PROENÇA, R.P.da C.; MATOS, C.H. Condições de trabalho e saúde na produção de refeições em creches municipais de Florianópolis, Rev. Cien. Saúde, Florianópolis, v. 15, n.1/2, p.73-84, jan./dez.1996.

- SIQUEIRA, M.M.M. Antecedentes de Comportamentos de Cidadania Organizacional: a análise de um modelo pós-cognitivo. Brasília, 1995. 267p. Tese (Doutorado em Psicologia) - Instituto de Psicologia, Universidade de Brasília.

- SNEED, J.; HERMAN, C. M. Influence of job characteristics and organizational commitment on job satisfaction of hospital foodservice employees. Journal of the American Dietetic Association, Knoxville, v.90, n. 8, p. 1072-1077, aug. 1990.

- VEIROS, M.B.; VIEIRA, A.M.; NERBASS, F.B.; ALVES, F.S.; MARQUES, L.F.; SILVA, R.C.; PROENÇA, R.P.C. Panorama da Qualidade de Vida dos Funcionários de uma Unidade de Alimentação e Nutrição. In: Congresso Brasileiro de Nutrição, 15., 1998, Brasília. Anais/Programa-019 Brasília: Associação Brasileira de Nutrição, 1998. p.34. 